\title{
Effect of the Neck Retraction Taping (NRT) on Forward Head Posture and the Upper Trapezius Muscle during Computer Work
}

\author{
WON-GYU YOO ${ }^{1)}$ \\ 1) Department of Physical Therapy, College of Biomedical Science and Engineering, Inje University \\ and Elderly Life Redesign Institute: 607 Obang-dong, Gimhae, Gyeongsangnam-do 621-749, \\ Republic of Korea. TEL+82 55-320-3994, FAX:+82 55-329-1678
}

\begin{abstract}
Purpose] The purpose of this study was to investigate the effect of neck retraction taping on forward head posture and the upper trapezius muscle of computer workers during computer work. [Subjects] Twelve males aged 20-30 years were recruited. [Methods] We measured forward head angle and upper trapezius muscle activity during computer work before and after NRT. [Results] The FHP angle significantly decreased during computer work performed with NRT compared to without NRT. The UT muscle activity was also significantly decreased during computer work performed with NRT compared to without NRT. [Conclusion] We think that the taping tension provided by NRT may have provided a mechanical effect that prevented FHP. NRT may also encourage a proper head posture in patients unfamiliar with the neck retraction posture.

Key words: Forward head posture, Neck retraction, Taping
\end{abstract}

(This article was submitted Nov. 30, 2012, and was accepted Dec. 29, 2012)

\section{INTRODUCTION}

One of the most common postural problems is the forward head posture (FHP). The repetitive use of computers has forced many computer users to adopt a FHP ${ }^{1,2)}$. For example, Szeto et al. ${ }^{1)}$ compared the head, neck, and shoulder postures of office workers with and without pain symptoms in these regions, while they were working in their actual work environments, and demonstrated trends of increased head tilt and neck flexion postures in the symptomatic subjects when compared to the asymptomatic subjects. When spinal tissues are subjected to a significant load for a sustained period of time, they deform and undergo remodeling changes that may become permanent ${ }^{2}$. Increased flexion at the atlanto-occipital joint increases the horizontal distance from the center of mass of the head to its axis of rotation, so that both atlanto-occipital and cervical flexion increase the torque required of the extensor musculature to maintain static equilibrium ${ }^{3}$. The elastic quality of Kinesio Tape (KT) may help to support or inhibit muscle function, support joint structure, reduce soft-tissue inflammation, reduce pain, and provide benefits to the sensorimotor and proprioceptive systems ${ }^{4}$. However, whether or not application of KT can exert an effect on forward head posture, or correct an incorrect head posture, has not yet determined. Hence, this study investigated the effect of neck retraction taping (NRT) on forward head posture and the activity of the upper trapezius muscles of computer workers while performing computer work.

E-mail:won7y@inje.ac.kr

\section{SUBJECTS AND METHODS}

Twelve males, aged 20-30 years with a mean height and weight of $170.3 \pm 4.2 \mathrm{~cm}$ and $65.9 \pm 5.1 \mathrm{~kg}$, respectively, participated in this study. The subjects had no history of musculoskeletal disorders or pain associated with the upper extremity in the past 6 months. At the atlantoccipital joint, the anterior transition of the head which defined as forward head posture (FHP), creates a long moment arm for the cervical extensor (CE) muscles counteracting the load of the head ${ }^{5}$. The long moment arm of CE results in a low muscular requirement of $\mathrm{CE}$, while increasing the activation of the upper trapezius; thus, weakness of CE is often found in patients with $\mathrm{FHP}^{6}$. Therefore, we decided that Neck Retraction Taping (NRT) should be applied to the CE muscles (acting on the neck retraction) of the subjects using Kinesio stretch tape. The tape was applied by a professional physical therapist, who was experienced in the application of Kinesio stretch tape, with a stretch of $15-25 \%{ }^{7)}$, while the subjects were in the upright standing position. For the $\mathrm{CE}$, the Kinesio tape was applied on both sides of the neck at the C4 T7 level. Kinematic data of the forward head posture was obtained before and after taping during 30 minutes of computer work. A 3-D ultrasonic motion analysis system (CMS-HS, Zebris, Medizintechnik, Isny, Germany) was used to measure the FHP angle of the head. The positions of the two markers were sampled at $20 \mathrm{~Hz}$. The markers were visible to the measuring sensor, which consisted of three microphones used to record the ultrasonic signals. The FHP angle was defined as the angle between a horizontal line drawn across the top of the spinous process of $\mathrm{C} 7$ and the line connecting the tragus of the ear to the spinous process 
of C7. The EMG data were collected using a Biopac MP100WSW (Biopac System, Santa Barbara, CA, USA) data acquisition system. The electrode site for the upper trapezius (UT) was located on the dominant right side $2 \mathrm{~cm}$ lateral to the midline drawn between the $\mathrm{C} 7$ spinous process and the posterolateral acromion. The Statistical Package for Social Sciences (SPSS, Chicago, IL, U.S.A.) was used to conduct the paired t-test to analyze the significance of difference between before and after taping. The level for statistical significance, $\alpha$, was chosen as 0.05 .

\section{RESULTS}

The FHP angle significantly decreased during computer work performed with NRT $\left(9.8 \pm 8.2^{\circ}\right)$ compared to without NRT $\left(23.0 \pm 12.5^{\circ}\right)(\mathrm{p}<0.05)$. The UT muscle activity also significantly decreased during computer work performed with NRT (11.5 $\pm 10.6 \%)$ compared to without NRT (27.1 \pm $13.5 \%)(\mathrm{p}<0.05)$

\section{DISCUSSION}

Forward head posture is a common clinical observation that patients presenting shoulder and back pain frequently demonstrate ${ }^{8)}$. Other postural correlates have also been described without quantitative verification, e.g. a forward tilted head is related to an extended upper cervical spine, or to protracted shoulder girdles and a kyphotic thoracic spine ${ }^{8)}$. Computer work involves prolonged viewing of a visual display unit and increased lower cervical flexion muscle tension to support the weight of the head ${ }^{9)}$ At the atlanto-occipital joint, anterior transition of the head, defined as FHP, creates a long moment arm for $\mathrm{CE}$ muscles counteracting the load of the head ${ }^{5)}$. The long moment arm for CE results in a low muscular requirement of $\mathrm{CE}$, while increasing the activation of the upper trapezius. Consequently, weakness of CE is often found in patients with $\mathrm{FHP}^{6}$. This study showed that the FHP angle significantly decreased during computer work performed with NRT compared to without NRT. The UT muscle activity was also significantly decreased during computer work performed with NRT compared to without NRT. It is known that the blood and lymph circulations may be enhanced at the sites where KT is applied; thus, the muscular and myofascial functions at those sites may also be affected ${ }^{10)}$. The application of KT to the skin may stimulate cutaneous mechanoreceptors, strengthen weak- ened muscles, and assist postural alignment ${ }^{11)}$. NRT may stimulate cutaneous mechanoreceptors, causing forward head posture and a return to the standard head posture by enhancing the functions of the CE muscle. In addition, KT was stretched more in FHP, and the increased tension may have provided a mechanical effect inhibiting FHP. Therefore, we think that NRT might aid in the prevention of FHP. NRT may also encourage a proper head posture in patients unfamiliar with the neck retraction posture.

\section{ACKNOWLEDGEMENT}

This research was supported by Basic Science Research Program through the National Research Foundation of Korea (NRF) funded by the Ministry of Education, Science and Technology (No. 2012001058).

\section{REFERENCES}

1) Szeto GP, Straker LM, O'Sullivan PB: A comparison of symptomatic and asymptomatic office workers performing monotonous keyboard work-2 neck and shoulder kinematics. Man Ther, 2005, 10: 281-291. [Medline] [CrossRef]

2) Gore DR, Sepic SB, Gardner GM: Roentgenographic findings of the cervical spine in asymptomatic people. Spine, 1986, 11: 521-524. [Medline] [CrossRef]

3) Burgess-Limerick R, Plooy A, Fraser K, et al.: The influence of computer monitor height on head and neck posture. Int J Ind Ergon, 1999, 23: 171179. [CrossRef]

4) Jaraczewska E, Long C: Kinesio ${ }^{\circledR}$ taping in stroke: improving functional use of the upper extremity in hemiplegia. Top Stroke Rehabil, 2006, 13: 31-42. [Medline] [CrossRef]

5) Neumann DA: Kinesiology of the musculoskeletal system: foundations for physical rehabilitation. St Louis: Mosby, 2002.

6) Szeto GP, Straker LM, O'Sullivan PB: A comparison of symptomatic and asymptomatic office workers performing monotonous keyboard work-1: neck and shoulder muscle recruitment patterns. Man Ther, 2005, 10: 270280. [Medline] [CrossRef]

7) Kase K, Wallis J: The latest Kinesio taping method. Tokyo: Ski-Journal, 2002.

8) Hanten WP, Lucio RM, Russell JL, et al.: Assessment of total head excursion and resting head posture. Arch Phys Med Rehabil, 1991, 72: 877-880. [Medline] [CrossRef]

9) Straker L, Mekhora K: An evaluation of visual display unit placement by electromyography, posture, discomfort and preference. Int J Ind Ergon, 2000, 26: 335-336. [CrossRef]

10) Yoshida A, Kahanov L: The effect of kinesio taping on lower trunk range of motions. Res Sports Med, 2007, 15: 103-112. [Medline] [CrossRef]

11) Kaya E, Zinnuroglu M, Tugcu I: Kinesio taping compared to physical therapy modalities for the treatment of shoulder impingement syndrome. Clin Rheumatol, 2011, 30: 201-207. [Medline] [CrossRef] 